\title{
Clinical development of liposome-based drugs: formulation, characterization, and therapeutic efficacy
}

This article was published in the following Dove Press journal:

International Journal of Nanomedicine

29 December 2011

Number of times this article has been viewed

\author{
Hsin-I Chang' \\ Ming-Kung Yeh ${ }^{2}$ \\ 'Department of Biochemical Science \\ and Technology, National Chia Yi \\ University, Chiayi City, ${ }^{2}$ Institute \\ of Preventive Medicine, National \\ Defence Medical Center, Sanhsia, \\ Taipei, Taiwan
}

\begin{abstract}
Research on liposome formulations has progressed from that on conventional vesicles to new generation liposomes, such as cationic liposomes, temperature sensitive liposomes, and virosomes, by modulating the formulation techniques and lipid composition. Many research papers focus on the correlation of blood circulation time and drug accumulation in target tissues with physicochemical properties of liposomal formulations, including particle size, membrane lamellarity, surface charge, permeability, encapsulation volume, shelf time, and release rate. This review is mainly to compare the therapeutic effect of current clinically approved liposomebased drugs with free drugs, and to also determine the clinical effect via liposomal variations in lipid composition. Furthermore, the major preclinical and clinical data related to the principal liposomal formulations are also summarized.
\end{abstract}

Keywords: PEGlated liposomes, temperature sensitive liposomes, therapeutic efficiency, virosomes, cationic liposomes

\section{Introduction}

The clinical utility of most conventional chemotherapeutics is limited either by the inability to deliver therapeutic drug concentrations to the target tissues or by severe and harmful toxic effects on normal organs and tissues. Liposomes are small, spherical, and enclosed compartments separating an aqueous medium from another by phospholipid bilayer. Many hundreds of drugs, including anticancer and antimicrobial agents, chelating agents, peptide hormones, enzymes, proteins, vaccines, and genetic materials, have been incorporated into the aqueous or lipid phases of liposomes, with various sizes, compositions, and other characteristics, to provide selective delivery to the target site for in vivo application. Several techniques, such as the Bangham, detergent-depletion, ether/ethanol injection, reverse phase evaporation, and emulsion methods, have been reported for preparing liposomes with high-entrapment efficiency, narrow particle size distribution, and long-term stability. ${ }^{1-7}$ Recently, some alternative methods including dense gas and supercritical fluid techniques have been introduced for liposome preparation without using any organic solvent. ${ }^{1,7-9}$ Due to the differences in preparation methods and lipid compositions, liposomes can be classified according to their lamellarity (uni- and multilamellar vesicles), size (small [ $\leq 100 \mathrm{~nm}$ ], intermediate [100-250 nm], or large [ $\geq 250 \mathrm{~nm}]$ ), and surface charge (anionic, cationic, or neutral). ${ }^{10-12}$ In clinical studies, liposomes show improved pharmacokinetics and biodistribution of therapeutic agents and thus minimize toxicity by their accumulation at the target tissue. ${ }^{13,14}$
Correspondence: Ming-Kung Yeh Institute of Preventive Medicine, National Defence Medical Center, Taipei, No I6I, Sec 6, Ming-chung E Rd,

Taipei City I 1490 , Taipei, Taiwan

Tel +886281777038 ext 19896

Fax +886226736954

Email mkyeh2004@gmail.com 
Liposomes were first discovered by Bangham in 1965 and the first liposomal pharmaceutical product, Doxil ${ }^{\circledR}$, (Ben Venue Laboratories, Inc Bedford, $\mathrm{OH}$ ) received US Food and Drug Administration (FDA) approval in 1995 for the treatment of chemotherapy refractory acquired immune deficiency syndrome (AIDS)-related Kaposi's sarcoma. ${ }^{13-15}$ Currently, there are about twelve liposome-based drugs approved for clinical use and more are in various stages of clinical trials (Tables 1 and 2). ${ }^{13-62}$ Most liposomal drug formulations, such as Doxil and Myocet $^{\mathrm{TM}}$ (GPPharm, Barcelona, Spain), are approved for intravenous application. ${ }^{63}$ Other administration routes such as intramuscular delivery have been approved for delivery of surface antigens derived from the hepatitis A or influenza virus (Epaxal ${ }^{\circledR}$ [Berna Biotech Ltd, Berne Switzerland] and Inflexal ${ }^{\circledR} \mathrm{V}$ [Berna Biotech España SA, Madrid, Spain]). ${ }^{37,38}$ Oral delivery has also been examined; however, this is more troublesome due to the potential for liposome breakdown following exposure to bile salts. ${ }^{64}$

\section{Storage of liposomes: lyophilization}

Liposomes dispersed in aqueous solution generally face physical and chemical instabilities after long-term storage. ${ }^{65}$ Hydrolysis and oxidation of phospholipids and liposome aggregation are the common cause of liposome instabilities. According to the literature, many methods have been investigated for the stabilization of liposomes, such as lyophilization, freezing, and spraying drying. In commercial liposome-based drugs (Table 1), AmBisome ${ }^{\circledR}$ (Gilead Sciences, Inc, San Dimas, CA), Amphotec ${ }^{\circledR}$ (Ben Venue Laboratories, Inc, Bedford, OH), Myocet, Visudyne ${ }^{\circledR}$ (Novartis Pharma AG, Basel, Switzerland), and LEP-ETU (liposome-entrapped paclitaxel easy-to-use; NeoPharm, Inc, Lake Bluff, IL) are all lyophilized products. In general, freeze-drying increases the shelf-life of liposomal formulations and preserves them in dried form as lyophilized cakes to be reconstituted with water for injection prior to administration. ${ }^{66}$ Furthermore, cryoprotectants need to be added to maintain particle size distribution of liposomes after the freeze-drying-rehydration cycle. Various types and concentrations of sugars have been investigated for their ability to protect liposomes against fusion and leakage during lyophilization processes. ${ }^{66}$ In commercial liposome lyophilized products, lactose has been used as a cryoprotectant in the formulations of Amphotec, Myocet, and Visudyne, and sucrose was added in the formulations of AmBisome and LEP-ETU to increase liposome stability during lyophilization. Interestingly, these commercial lyophilized products showed similar shelf-life in comparison with other liposome products (eg, suspension and emulsions) and hence lyophilization may not have the expected effect on liposome stability. In 1998, Clemons and Stevens compared the potency and therapeutic efficacy among the different lipid-based formulations of amphotericin B (Amphotec, AmBisome, and Abelcet $^{\circledR}$ (Sigma-Tau PharmaSource, Inc, Indianapolis, IN)) for the treatment of systemic and meningeal cryptococcal disease. ${ }^{67}$ Their work indicated that the therapeutic efficacy of Amphotec and AmBisome was superior to that of Abelcet, by up to ten-fold, in survival and in clearing infection from all organs. In these three commercially available lipid-based formulations of amphotericin B, Amphotec and AmBisome are both lyophilized products and Abelcet is formulated as a suspension. Therefore, lyophilization may not extend the shelf-life of products but may increase therapeutic efficacy in vivo. Similar results were also reported in our previous studies. ${ }^{70}$ We investigated the stability of the siRNA-loaded liposomes in suspension and lyophilized powder form up to 1 month postmanufacture. ${ }^{68}$ Following formulation, the siRNA-loaded liposomes were stored at either $4^{\circ} \mathrm{C}$ or room temperature. The particle size and zeta potential of siRNAloaded liposomes remained unchanged in both storage conditions. However, siRNA entrapment efficiencies were observed to have decreased slightly after 1 month in storage for both suspension $(90 \% \rightarrow 83 \%)$ and lyophilized powder $(94 \% \rightarrow 84 \%)$ forms. Surprisingly, the gene-silencing efficiency of siRNA-loaded liposomes in aqueous solution showed $80 \%$ reduction following 1 month of storage at either $4^{\circ} \mathrm{C}$ or room temperature. This was in contrast to liposomes prepared in the lyophilized powder form where $100 \%$ of the gene-silencing efficiency was retained following storage at either $4^{\circ} \mathrm{C}$ or room temperature for 1 month. Although therapeutic efficiency of liposome-based drugs may vary depending on the choice of lipids, the preparation technique, physico-chemical characteristics of the bioactive materials, and overall charge of the liposome, lyophilization is useful for the long-term storage of liposome-based drugs.

\section{Clinical studies of liposomal-based anticancer drugs: doxorubicin}

Liposome delivery systems offer the potential to enhance the therapeutic index of anticancer drugs, either by increasing the drug concentration in tumor cells or by decreasing the exposure in normal host tissues. Doxorubicin is an anthracycline widely used to treat solid and hematological tumors, but its major drawback is its related cardiotoxicity. In cardiotoxicity, positively charged doxorubicin's affinity for negatively charged cardiolipin, a lipid abundant in heart tissue, is thought to be involved in drug localization in the heart tissue. ${ }^{69}$ Therefore, doxorubicin-loaded liposomes were developed to combat 


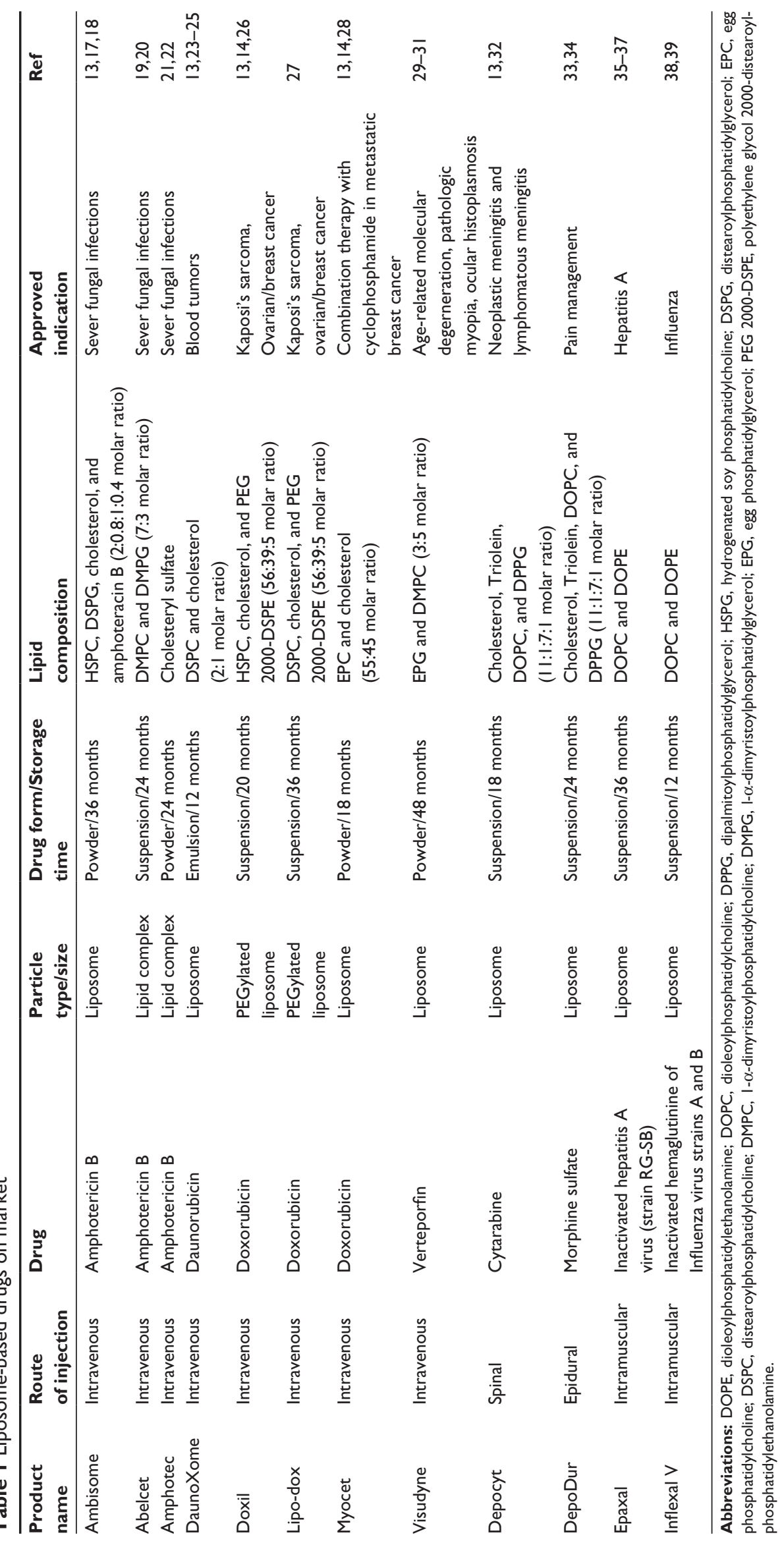




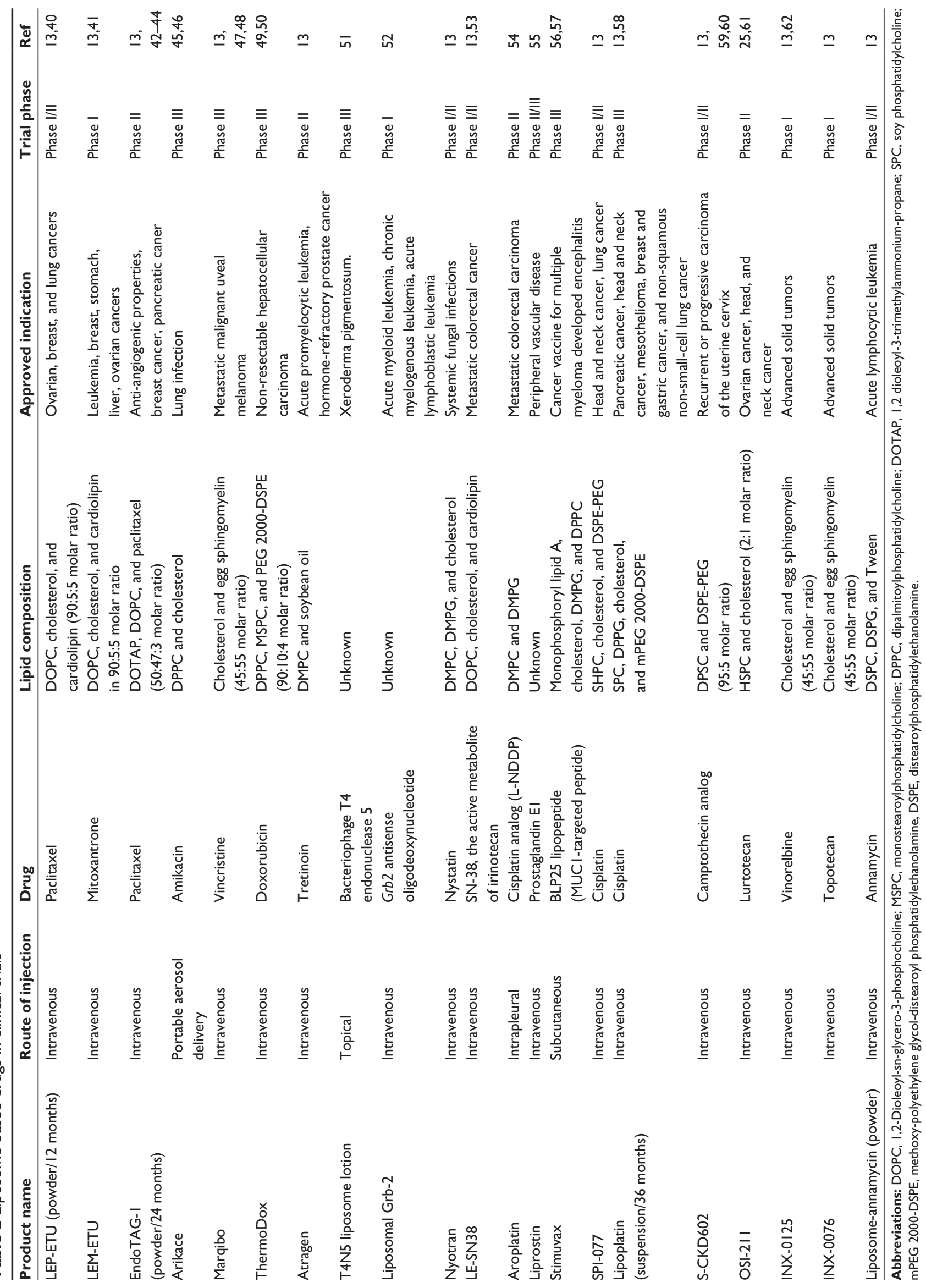


aggressive tumors, like breast and ovary metastatic cancers and Kaposi's sarcoma. Myocet and Doxil were the first-approved liposome-based drugs for cancer treatment. Both products contain doxorubicin but are different, particularly in the presence of polyethylene glycol (PEG) coating (Figure 1). In pharmacokinetic studies of doxorubicin-loaded liposomes, free doxorubicin had an elimination half-life of 0.2 hours and an area under the plasma concentration-time curve (AU) of $4 \mu \mathrm{gh}$ $\mathrm{mL}^{-1}$ in patients as compared with 2.5 hours and $45 \mu \mathrm{g} \mathrm{h} \mathrm{mL}^{-1}$ for Myocet and with 55 hours and $900 \mu \mathrm{g} \mathrm{h} \mathrm{mL} \mathrm{m}^{-1}$ for Doxil, respectively. ${ }^{25}$ The particle size of Myocet is about $190 \mathrm{~nm}$ and
Doxil is about $100 \mathrm{~nm}$. Both liposome products have longer circulating half-life in blood as compared with the free drug, but Doxil has a much longer circulation time in blood than Myocet. Generally, the blood circulation time of liposomes $\left(T_{1 / 2}\right)$ increases with decreasing size, negative charge density, and fluidity in the bilayer or PEG surface coating. In a Phase III head-to-head comparison of free doxorubicin vs Myocet in patients with metastatic breast cancer, similar results were presented in first-year survival rate (64\% vs 69\%) and progression-free survival (3.8 vs 4.3 months), but Myocet had low incidence of cardiac events (13\% vs 29\%),

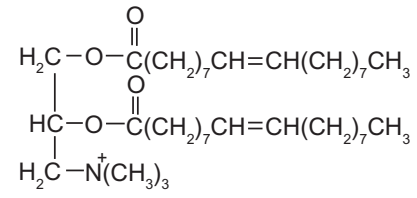

DOTAP<smiles>CCCCCCC(=O)OCC(O)COP(=O)([O-])OCCN(C)C</smiles>

MSPC

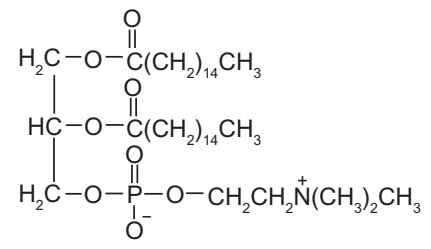

HSPC<smiles>CCCCCCOP1([O-])(OCC)OCC2COC(C)(OC2)O1</smiles>

DOPC

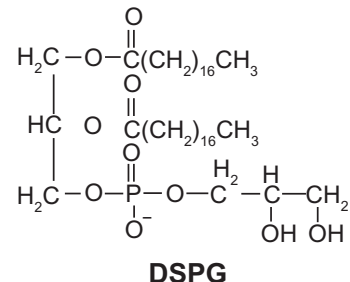

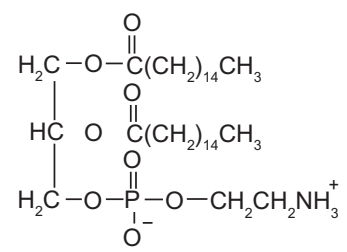

DPPC

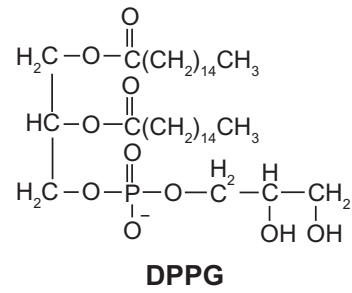

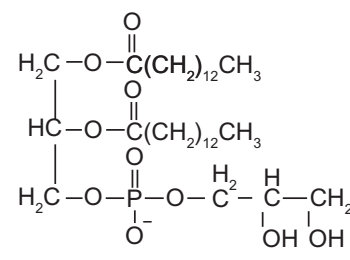

DMPG

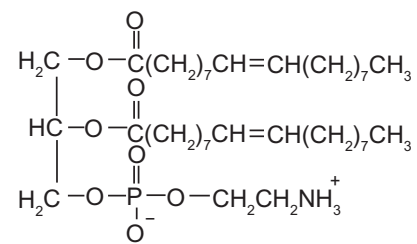

DOPE

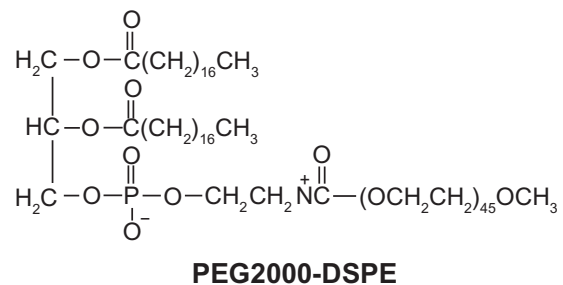

Figure I Chemical structures of lipids in liposome formulations.

Abbreviations: DOTAP, I,2-dioleoyl-3-trimethylammonium propane; DPPC, dipalmitoylphosphatidylcholine; DOPA, I,2-Dioleoyl-sn-Glycero-3-Phosphate; MSPC, monostearoylphosphatidylcholine; DPPG, dipalmitoylphosphatidylglycerol; DSPC, distearoylphosphatidylcholine; HSPC, hydrogenated soy PC; DMPG, I- $\alpha$ dimyristoylphosphatidylglycerol; DMPC, I- $\alpha$-dimyristoylphosphatidylcholine; DOPC, I,2-Dioleoyl-sn-glycero-3-phosphocholine; DOPE, dioleoyl phosphatidylethanolamine; DSPG, distearoylphosphatidylglycerol; PEG2000-DSPE, polyethylene glycol 2000-distearoylphosphatidylethanolamine. 
mucositis/stomatitis ( $8.6 \%$ vs $11.9 \%$ ), and nausea/vomiting (12.3\% vs 20.3\%). ${ }^{70,71}$ Therefore, Myocet tends to reduce drug-related toxicity (eg, cardiotoxicity) rather than to enhance antitumor efficacy. Similar to Myocet, Doxil had a better safety profile, including reduction of cardiotoxicity (3.9\% vs $18.8 \%$ ), neutropenia ( $4 \%$ vs 10\%), vomiting (19\% vs 31\%), and alopecia $(20 \%$ vs $66 \%)$ in a Phase III trial of metastatic breast cancer, whereas its progression-free survival times (6.9 vs 7.8 months) and overall survival times (21 vs 22 months) demonstrated equivalent efficacy to conventional doxorubicin. ${ }^{72}$ However, palmar-plantar erythrodysesthesia (48\% vs $2 \%$ ), stomatitis ( $22 \%$ vs $15 \%$ ), and mucositis ( $23 \%$ vs $13 \%$ ) were found to be more often associated with Doxil than free doxorubicin.

Lipo-dox ${ }^{\circledR}$ (TTY Biopharm Company Ltd, Taipei Taiwan) is the second generation of PEGylated liposomal doxorubicin, composed of distearoylphosphatidylcholine (DSPC) and cholesterol with a surface coating of PEG. ${ }^{27}$ DSPC, which has two completely saturated fatty acids (both stearic acids), has high phase-transition temperature $(\mathrm{Tm}), 55^{\circ} \mathrm{C}$, and good compatibility with cholesterol. Normally, lipid bilayer has two thermodynamic phases: gel or liquid-crystal phase. At temperature $<$ Tm, the lipid membrane is in the gel phase, which is relatively rigid and tight because the lipid molecules have lower energy of random motion and the hydrocarbon chains are fully extended and closely packed. Liposomes composed of phospholipids like DSPC have higher stability compared with others containing unsaturated fatty acid (egg phosphatidycholine [PC]) or fatty acids of shorter or not uniform carbon chains like hydrogenated soy PC (HSPC). In a Phase I clinical study, Lipo-dox achieved the most prolonged circulation half-life (65 hours). ${ }^{73}$ However, Tseng et al demonstrated that there were no differences in survival between free doxorubicin only (median survival time of 23 days) and Lipo-dox (medium survival time of 23.5 days) in a murine B-cell lymphoma model. ${ }^{74}$ In patients with metastatic breast cancer, the median time to disease progression of 163 days represented the result of Lipo-dox treatment and the median duration of response in responding patients (286 days) are comparable with those of Doxil treatment. ${ }^{75}$ Neutropenia, stomatitis, and skin toxicity were reported in many cases of Lipo-dox administration. Moreover, stomatitis became the new dose-limiting toxicity of PEGylated liposomal doxorubicin. For Lipo-dox, stomatitis appeared at doses of $30 \mathrm{mg} / \mathrm{m}^{2}$ and reached dose limit at $50 \mathrm{mg} / \mathrm{m}^{2}{ }^{27}$ In contrast, Doxil reached dose limit at $80 \mathrm{mg} / \mathrm{m}^{2}$ and hence Lipo-dox had higher incidence of severe stomatitis than Doxil. In comparison with Myocet (the non-PEGylated form of liposomal doxorubicin), Doxil and Lipo-dox (both PEGylated forms of liposomal doxorubicin) both showed significant incidence of stomatitis and this is mainly due to the long circulation properties of PEGylated liposomes. . $7,71,72^{2}$

The new generation of doxorubicin-loaded liposomes are thermosensitive liposomes (TSLs), which release their encapsulated drugs in regions where local tissue temperatures are elevated. ${ }^{76}$ Compared with non-TSLs that remain stable and do not release drug in the physiologic temperature range, TSLs undergo a gel-to-liquid crystalline phase change when heated that renders the liposomes more permeable, releasing their encapsulated drugs. ThermoDox ${ }^{\circledR}$ (Celsion Corporation, Lawrenceville, NJ), a proprietary TSL encapsulation of doxorubicin, has recently begun Phase III clinical trials for the treatment of hepatocellular carcinoma. ${ }^{77}$ ThermoDox is composed of dipalmitoylphosphatidylcholine (DPPC), monostearoylphosphatidylcholine (MSPC), and polyethylene glycol 2000-distearoylphosphatidylethanolamine (PEG 2000-DSPE) in 90:10:4 molar ratio. ${ }^{49,50}$ In the design of TSLs, it is necessary to choose a phospholipid that has a gel-to-liquid crystalline phase transition temperature (Tc) in the temperature range of clinically attainable local hyperthermia $\left(41^{\circ} \mathrm{C}-42^{\circ} \mathrm{C}\right)$. The mechanism behind TSLs is the temperature-induced membrane instability at the Tc of the used lipids. DPPC with a Tc $=41.5^{\circ} \mathrm{C}$ is an ideal lipid according to temperature-triggered technology. ${ }^{78,79}$ For liposomes composed of DPPC alone, the rate of release and the amount released are relatively small. By incorporating a small amount of lysolipids, such as MSPC or monopalmitoylphosphatidylcholine, into DPPC liposomes, Tc is shifted down slightly and membrane instability and drug release rate is significantly enhanced at Tc. In vitro release studies, monopalmitoylphosphatidylcholine-containing TSLs released about $45 \%$ of encapsulated doxorubicin in bovine serum at $42^{\circ} \mathrm{C}$ in a few seconds (20 seconds), while pure DPPC liposomes released only $20 \%$ over 1 hour. ${ }^{79}$ Banno et al demonstrated that the presence of MSPC, rather than PEG 2000-DSPE, in DPPC liposomes would give rise to the rapid drug-release profile in vitro, suggesting that lysolipid is the more important component in determining the rate of TSL content release. ${ }^{80}$ Indeed, Banno's in vivo data showed that the presence of $9.6 \mathrm{~mol} \% \mathrm{MSPC}$ in TSL could result in more rapid elimination of the encapsulated doxorubicin $\left(\mathrm{T}_{1 / 2}=1.29 \mathrm{~h}\right)$, compared with the formulation without lysolipid $\left(\mathrm{T}_{1 / 2}=2.91 \mathrm{~h}\right)$. In 2007 , Dromi et al compared the accumulation of doxorubicin in mice tumors among free doxorubicin, Doxil, and ThermoDox..$^{50}$ Results showed that over time, doxorubicin gradually increased in tumors when both Doxil and ThermoDox were used but not with free doxorubicin. At 24 hours after administration, doxorubicin concentrations in tumors were found to be significantly higher 
with Doxil than ThermoDox. ThermoDox is currently under evaluation in clinical trials and hence the therapeutic efficacy of ThermoDox is still unknown.

\section{Clinical studies of liposomal-based anticancer drugs: daunorubicin}

Daunorubicin is classified as an anthracycline anticancer drug in the treatment of leukemia and a wide variety of solid tumors, but its major drawbacks are myelosuppression and cardiotoxicity. ${ }^{81}$ Daunorubicin has also been incorporated into liposomes for the formulation of liposomal anticancer chemotherapy drugs. DaunoXome ${ }^{\circledR}$ (Gilead Sciences, Inc) is a commercial liposomal formulation of daunorubicin in which the drug is entrapped into small unilamellar vesicles $(45 \mathrm{~nm})$ composed of DSPC and cholesterol in 2:1 molar ratio. In animal studies with tumor models in mice, DaunoXome increased tumor uptake of daunorubicin ten-fold when measured against free drug (2470.5 vs $245.1 \mu \mathrm{g} \cdot \mathrm{hr} / \mathrm{mL}$ for 0-48 hours). ${ }^{82}$ Furthermore, clinical pharmacokinetic studies have demonstrated that DaunoXome was 36-fold higher in AUC (375.3 vs $10.33 \mu \mathrm{g} \cdot \mathrm{hr} / \mathrm{mL})$ in comparison with conventional daunorubicin. ${ }^{83}$ In a Phase III trial of DaunoXome versus a conventional combination of doxorubicin, bleomycin, and vincristine (ABV) in AIDS-related Kaposi's sarcoma, the efficacy of DaunoXome was comparable to that of vincristine. Response rates (25\% vs $28 \%$ ), time to treatment failure (115 vs 99 days), and overall survival (369 vs 342 days) were similar on both treatment arms. ${ }^{84}$ Moreover, patients treated with DaunoXome experienced less alopecia ( $8 \%$ vs $36 \%$ ) and neuropathy (13\% vs $41 \%$ ) and their cardiac function remained stable. Therefore, DaunoXome may provide another comparable but safer chemotherapy.

\section{Clinical studies of liposomal-based anticancer drugs: paclitaxel}

Taxol $^{\circledR}$ (paclitaxel) is a marketed product for the treatment of ovarian, breast, non-small cell lung cancer, and AIDS-related Kaposi's sarcoma. ${ }^{40}$ However, paclitaxel is only sparingly soluble in water and, therefore, intravenous administration depends on the use of the non-ionic surfactant Cremophor $\mathrm{EL}^{\circledR}$ (polyethoxylated castor oil) to achieve a clinically relevant concentrated solution. Unfortunately, Cremophor EL increases toxicity and leads to hypersensitivity reactions in certain patients. ${ }^{85}$ The LEP-ETU formulation of paclitaxel is being developed to potentially reduce toxicities associated with Taxol by eliminating the drug formulation component polyoxyethylated castor oil. LEP-ETU formulations composed of 1,2-Dioleoyl-sn-glycero-3-phosphocholine
(DOPC), cholesterol, and cardiolipin in 90:5:5 molar ratio were prepared by the modified thin-film hydration method. DOPC, a zwitterionic natural phospholipid, is chosen as one of the lipid components in the LEP-ETU formulation because of a low $\mathrm{Tc}\left(-22^{\circ} \mathrm{C}\right)$ and hence DOPC can form more flexible liposomes to entrap highly hydrophobic molecules. Moreover, cholesterol is included in LEP-ETU formulations to increase the liposome stability. Liposomes containing cardiolipin reportedly reduced cardiotoxicity associated with doxorubicin by altering the pharmacokinetics and tissue distribution of the drug and hence cardiolipin may also exert similar results in LEP-ETU. ${ }^{86}$ Fetterly et al evaluated the maximum tolerated dose, dose-limiting toxicities, and pharmacokinetics of liposome-encapsulated paclitaxel (LEP-ETU) in comparison with Taxol. ${ }^{87,88}$ The maximum tolerated dose of LEP-ETU was $325 \mathrm{mg} / \mathrm{m}^{2}$ in a Phase I study of patients with locally advanced or metastatic carcinoma. ${ }^{88,89}$ This dose is higher than that achieved with Taxol, which is typically delivered at a dose range of 135 to $200 \mathrm{mg} / \mathrm{m}^{2}$. The major toxicity to administration of paclitaxel is neuropathy. In the Phase I study, neurotoxicity occurred in 5 of 12 patients $(42 \%)$ treated with LEP-ETU at $\geq 325 \mathrm{mg} / \mathrm{m}^{2}$. Although a direct comparison with Taxol is not possible, neutropenia was seen in $53 \%$ of metastatic breast cancer patients treated with $250 \mathrm{mg} / \mathrm{m}^{2}$ Taxol as demonstrated by Winer et al. ${ }^{89}$ Therefore, the neuropathy caused by LEP-ETU appears to be no worse than that reported for Taxol within 3 weeks of treatment. Following LEP-ETU administration, the AUC of paclitaxel in patients with advanced or metastatic carcinoma was improved ( 8.2 to $6.16 \mu \mathrm{g} \cdot \mathrm{hr} / \mathrm{mL}$ ) with increasing dose (135 to $375 \mathrm{mg} / \mathrm{m}^{2}$ ), which is similar to Taxol. Although similarities exist between the plasma pharmacokinetics of the two formulations, the clinical evidence obtained from the Phase I study shows LEP-ETU can be administered safely at higher doses than Taxol. ${ }^{88,89}$

Another liposome formation of paclitaxel is EndoTAG-1. ${ }^{42-44}$ The formulation of EndoTAG-1 is prepared by 1,2-dioleoyl-3-trimethylammonium propane (DOTAP), DOPC, and paclitaxel in 50:47:3 molar ratio. DOTAP is a cationic synthetic lipid, which comprises one positive charge at the head group. The use of cationic lipids to enhance gene delivery has been studied extensively, but their application in clinic is relatively unexplored. Recently, there has been great interest in cationic liposomes, mainly due to their inherent ability to selectively target tumor vasculature. This selective affinity of cationic liposomes to tumor vasculature provides an opportunity for the development of many antiangiogenic and anticancer formulations based on cationic 
liposomes. ${ }^{42}$ EndoTAG-1 is the first formulation of cationic liposomes carrying paclitaxel in clinical trial. For commercial storage, EndoTAG-1 formulations are lyophilized, and they are reconstituted with water for injection directly prior use. In preclinical programs, EndoTAG1-1 inhibited tumor growth also in Taxol-resistant animal tumor models such as B16 melanoma and Sk-Mel 28 melanoma. EndoTAG-1 demonstrated a strong antivascular effect on the preexisting tumor vasculature and affected several tumor microcirculatory parameters. In a Phase II trial of patients with pancreatic adenocarcinoma who were not candidates for surgery, EndoTAG-1 in combination with gemcitabine substantially extended overall survival compared with gemcitabine alone..$^{90}$ Median survival in patients who received gemcitabine alone was 7.2 months, whereas it was up to 9.4 months in those who received combination treatment of EndoTAG-1 plus gemcitabine. After 6 and 12 months of treatment, survival rate was superior for all EndoTAG-1 doses plus gemcitabine compared with gemcitabine alone. The 12-month survival rates in patients given the two higher doses of EndoTAG-1 (22 and $44 \mathrm{mg} / \mathrm{m}^{2}$ plus gemcitabine) were $36 \%$ and $33 \%$, respectively, compared with $17.5 \%$ in those given gemcitabine alone. Combination treatment with EndoTAG-1 plus gemcitabine was well tolerated and led to substantially more prolonged survival rates compared with standard therapy in this Phase II trial. Further clinical studies are warranted to demonstrate a statistically significant survival benefit associated with EndoTAG-1 plus gemcitabine in advanced pancreatic cancer.

\section{Liposome application in vaccine formulation: Epaxal and Inflexal V}

The incorporation of viral membrane proteins or peptide antigens into liposomes has been shown to potentiate cellmediated and humoral immune response, and generate solid and durable immunity against the pathogen. Virosomes are reconstituted virus liposomes, constructed without the genetic information of the virus making them unable to replicate or cause infection..$^{91,92}$ The lipid layers of virosomes, composed of dioleoyl phosphatidylethanolamine (DOPE) and DOPC, are employed to mimic viral membrane for vaccine delivery. Epaxal and Inflexal $\mathrm{V}$ are both vaccine products using the virosome-based antigen delivery system for commercial use (Table 1). For the production of Inflexal V, the influenza viruses, grown in hens' eggs, are first inactivated with beta-propiolactone. The influenza surface antigens, hemagglutinin and neuraminidase, are then purified and mixed with the phospholipid lecithin to form virosomes.
Due to the virosomal technology, hepatitis A virus (HAV) vaccine Epaxal, and influenza vaccine Inflexal $\mathrm{V}$ are highly efficacious by mimicking natural viral infection. The use of virosomes to deliver hepatitis A or influenza antigens stimulates a strong immune response of immunocompetent cells. In contrast to other commercially available HAV vaccines, Epaxal is an aluminium-free vaccine based on formalininactivated hepatitis A (strain RG-SB) antigen-incorporated virosomes. In a clinical study by Usonis et al, seroprotection rates were $100 \%$ in all infants and children at 1 and 12 months after primary vaccination with Epaxal. ${ }^{35}$ In contrast, the seroprotection rate after vaccination with the aluminiumcontaining vaccine Havrix ${ }^{\mathrm{TM}}$ (GlaxoSmithKline Biologicals Rixensart, Belgium) was $67.7 \%$ in infants with pre-existing maternal anti-HAV antibodies, and a booster vaccination was required for complete seroprotection. Moreover, Epaxal was generally well tolerated by infants and children, with no serious systemic or local events reported after either primary or booster vaccination.

For Inflexal V, most studies have shown inferior efficacy or ineffectiveness on clinical parameters for these vaccines compared with the nonadjuvanted, split-virus, or subunit seasonal vaccines. ${ }^{93}$ Kanra et al, compared the immunogenicity and safety of Inflexal V in children with a split influenza vaccine, Fluarix (GlaxoSmithKline Biologicals, Dresden, Germany). ${ }^{94}$ Both vaccines were well tolerated and could induce effective immune responses in children. Interestingly, the virosome-adjuvanted influenza vaccine showed greater immunogenicity ( $88.8 \%$ seroconversion rates for H3 N2) over the split influenza vaccine $(77.5 \%$ seroconversion rates for H3 N2) in unprimed children. In essence, virosomal techniques may not be able to give superior protective immunity in clinic but play an important role in preventing morbidity and lethality associated with vaccine.

\section{Liposomal formulations in ophthalmology: Visudyne ${ }^{\circledR}$}

Verteporfin is a hydrophobic chlorin-like photosensitizer, which has been shown to be highly effective for photodynamic therapy in vivo. However, verteporfin also has a tendency to undergo self-aggregation in aqueous media, which can severely limit drug bioavailability to biological systems. It is important to introduce verteporfin into the bloodstream in its monomeric form and hence verteporfin was encapsulated in liposomes (Visudyne) for intravenous drug delivery. ${ }^{29-31}$ The lipid layers of Visudyne are composed of unsaturated egg phosphatidylglycerol and dimyristoyl phosphatidyl choline in 3:5 molar ratio. Visudyne was the 
only drug approved by the FDA for the photodynamic treatment of age-related macular degeneration. Visudyne treatment prevents the growth of the destructive blood vessels without hurting the surrounding tissues. Phase I and II clinical trials were conducted for 609 patients with age-related macular degeneration. ${ }^{95,96}$ After 12 months of treatment, the group treated with Visudyne $\left(6 \mathrm{mg} / \mathrm{m}^{2}\right.$ body surface area) had statistically better visual acuity, contrast sensitivity, and fluorescein angiographic outcomes than those who had placebo treatment ( $5 \%$ dextrose in water). At the examination 12-months posttreatment, 246 (61\%) of 402 eyes assigned to verteporfin compared with 96 (46\%) of 207 eyes assigned to placebo had lost fewer than 15 letters of visual acuity from baseline. In subgroup analyses, the visual acuity benefit of verteporfin therapy was clearly demonstrated (67\% vs 39\%) when the area of choroidal neovascularization, caused by age-related macular degeneration, occupied $50 \%$ or more of the area of the entire lesion. However, Chowdhary et al reported that Visudyne was readily destabilized in the presence of relatively low concentrations of plasma. ${ }^{29}$ Therefore, the aim of future investigation of liposomal formulations in ophthalmology is to develop stable liposome structures for extending the plasma circulation time following intravenous injection.

\section{Future approaches}

Since the first liposomal pharmaceutical product, Doxil, received FDA approval in 1995, liposomes have been widely applied as drug carriers in clinic. Until now, several important types of liposomes, such as PEGylated liposomes (Doxil and Lipo-dox), temperature sensitive liposomes (ThermoDox), cationic liposomes (EndoTAG1-1), and virosomes (Expal and Inflexal V) have been investigated for clinic use. In contrast with liposomal-based drugs on the market (Table 1), liposome-based drugs in clinical trials (Table 2) focused more on the types of delivered drugs (eg, Cisplatin, BLP25 lipopeptide, Grb2 antisense oligodeoxynucleotide, Bacteriophage T4 endonuclease 5, etc) and therapeutic applications (from topical delivery systems to portable aerosol delivery systems). New liposomal formulations, such as PEGylated liposomes, may extend blood circulation time, vary drug distribution in the body, and hence reduce the possible side effects related to the drugs (eg, cardiotoxicity). However, PEGylated liposomes (Doxil and Lipo-dox) displayed significant incidence of stomatitis in clinical trials, which may be related to PEGylation. Moreover, some of the new generation liposomes showed only comparable or even poor therapeutic efficiency compared with free drug or conventional vesicles in clinical trials. In comparison with Doxil, ThermoDox displayed significantly weaker doxorubicin accumulation in mice tumors at 24 hours after administration. ${ }^{50}$ EndoTAG-1 plus gemcitabine and EndoTAG-1 plus paclitaxel achieved excellent therapeutic effect in two Phase II clinical trials in pancreatic cancer and triple receptor-negative breast cancer, but EndoTAG-1 therapy alone in triple receptor-negative breast cancer resulted in poor survival rate (34\%) and median progression-free survival time (3.4 months) in comparison with paclitaxel (48\% and 3.7 months). ${ }^{97}$ SPI-077, the first liposomal formulation of cisplatin, had limited clinical efficacy in a Phase II clinical trial of advanced non-small cell lung cancer, even though SPI-077 demonstrated enhanced cisplatin tumor accumulation in preclinical models. ${ }^{98}$ Similar to SPI-077, a Phase II study of liposomal annamycin in the treatment of doxorubicin-resistant breast cancer had no detectable antitumor activity. ${ }^{99}$ Although new liposomalbased drugs have been well studied in preclinical animal models, these liposomal pharmaceutical products may be unable to provide promising therapeutic effects in clinical trials. For future development of liposomal-based drugs, the comparison of drug circulation time in blood, drug accumulation in tissues, and possible toxicity between conventional vesicles and new generations of liposomes should be investigated in preclinical animal models. Furthermore, there should also be focus on the clinical therapeutic effects and toxic side effects of liposomal lipid composition.

\section{Acknowledgment}

This work was supported by the National Science Council (Taiwan) (grant numbers: NSC 98-2320-B-415-001-MY3 and NSC 98-2320-B-016-003-MY3).

\section{Disclosure}

The authors report no conflicts of interest in this work.

\section{References}

1. Otake K, Imura T, Sakai H, Abe M. Development of a new preparation method of liposomes using supercritical carbon dioxide. Langmuir. 2001;17(13):3898-3901.

2. Uhumwangho MU, Okor RS. Current trends in the production and biomedical applications of liposomes: a review. Pak J Pharm Sci. 2005; 4(1):9-21

3. Jiskoot W, Teerlink T, Beuvery EC, Crommelin DJ. Preparation of liposomes via detergent removal from mixed micelles by dilution. The effect of bilayer composition and process parameters on liposome characteristics. Pharm Weekbl Sci. 1986;8(5):259-265.

4. Deamer QW. Preparation and properties of ether-injection liposomes Ann N Y Acad Sci. 1978;308:250-258.

5. Szoka F Jr, Papahadjopoulos D. Procedure for preparation of liposomes with large internal aqueous space and high capture by reverse-phase evaporation. Proc Natl Acad Sci U S A. 1978;75(9):4194-4198. 
6. Kim S, Martin GM. Preparation of cell-size unilamellar liposomes with high captured volume and defined size distribution. Biochim Biophys Acta. 1981;646(1):1-9.

7. Meure LA, Foster NR, Dehghani F. Conventional and dense gas techniques for the production of liposomes: a review. AAPS Pharm Sci Tech. 2008;9(3):798-809.

8. Lesoin L, Boutin O, Crampon C, Badens E. CO2/water/surfactant ternary systems and liposome formation using supercritical CO2: a review. Colloid Surface Physicochem Eng Aspect. 2011;377(1-3):1-14.

9. Castor TP. Phospholipid nanosomes. Curr Drug Deliv. 2005;2(4): 329-340.

10. Jesorka A, Orwar O. Liposomes: technologies and analytical applications. Annu Rev Anal Chem (Palo Alto Calif). 2008;1:801-832.

11. Makino K, Shibata A. Chapter 2: Surface properties of liposomes depending on their composition. In: Leitmannova Liu A, editor. Advances in Planar Lipid Bilayers and Liposomes. Netherlands: Elsvier Science; 2006;4:49-77.

12. Irache JM, Esparza I, Gamazo C, Agüeros M, Espuelas S. Nanomedicine: novel approaches in human and veterinary therapeutics. Vet Parasitol. 2001;180(1-2):47-71.

13. Immordino ML, Dosio F, Cattel L. Stealth liposomes: review of the basic science, rationale, and clinical applications, existing and potential. Int J Nanomedicine. 2006;1(3):297-315.

14. Park JW. Liposome-based drug delivery in breast cancer treatment. Breast Cancer Res. 2002;4(3):95-99.

15. Bangham AD. Diffusion of univalent ions across unilamellar of swollen phospholipids. J Mol Biol. 1965;13:238-252.

16. Allen TM, Moase EH. Therapeutic opportunities for targeted liposomal drug delivery. Adv Drug Deliv Rev. 1996;21(2):117-133.

17. Astellas Pharma US, Inc [homepage on the Internet]. AmBisome ${ }^{\circledR}$ (Amphotericin B) liposome for injection. Available from: http://www. ambisome.com/. Accessed November 11, 2011.

18. Meunier F, Prentice HG, Ringdén O. Liposomal amphotericin B (AmBisome): safety data from a phase II/III clinical trial. JAntimicrob Chemother. 1991;28 Suppl B:83-91.

19. Enzon Pharmaceuticals, Inc [homepage on the Internet]. ABELCET ${ }^{\circledR}$ (amphotericin B lipid complex) Injection. Available from: http://enzon. com/. Accessed November 11, 2011.

20. Wasan KM, Lopez-Berestein G. Characteristics of lipid-based formulations that influence their biological behavior in the plasma of patients. Clin Infect Dis. 1996;23(5):1126-1138.

21. Denning DW, Lee JY, Hostetler JS, et al. NIAID Mycoses Study Group multicenter trial of oral itraconazole therapy for invasive aspergillosis. Am J Med. 1994;97:135-144.

22. Three Rivers Pharmaceuticals, LLC. [homepage on the Internet]. AMPHOTEC $^{\circledR}$ Amphotericin B Cholesteryl Sulfate Complex for Injection. Available from: http://www.3riverspharma.com/. Accessed November 11, 2011.

23. Gilead Sciences, Inc [homepage on the Internet]. DaunoXome ${ }^{\circledR}$ (daunorubicin citrate liposome injection). Available from: http://www. gilead.com/. Accessed November 11, 2011.

24. Rivera E. Liposomal anthracyclines in metastatic breast cancer: clinical update. Oncologist. 2003;8 Suppl 2:3-9.

25. Tomkinson B, Bendele R, Giles FJ, et al. OSI-211, a novel liposomal topoisomerase I inhibitor, is active in SCID mouse models of human AML and ALL. Leuk Res. 2003;27(11):1039-1050.

26. Hoarau D, Delmas P, David S, Roux E, Leroux JC. Novel long-circulating lipid nanocapsules. Pharm Res. 2004;21(10): 1783-1789

27. Hong RL. Liposomal anti-cancer drug researches the myth of long circulation. J Chinese Oncol Soc. 2004;20(2):10-21.

28. Gardikis K, Tsimplouli C, Dimas K, Micha-Screttas M, Demetzos C. New chimeric advanced Drug Delivery nano Systems (chi-aDDnSs) as doxorubicin carriers. Int J Pharm. 2010;402(1-2):231-237.

29. Chowdhary RK, Shariff I, Dolphin D. Drug release characteristics of lipid based benzoporphyrin derivative. J Pharm Pharmaceut Sci. 2003;6(1):13-19.
30. Fahr A, van Hoogevest P, May S, Bergstrand N, S Leigh ML. Transfer of lipophilic drugs between liposomal membranes and biological interfaces: consequences for drug delivery. Eur J Pharm Sci. 2005;26(3-4):251-265.

31. Novartis Ophthalmics, Inc [homepage on the Internet]. Visudyne ${ }^{\circledR}$ (verteporfin for injection). Available from: http://www.visudyne.com/. Accessed November 11, 2011.

32. Drugs.com [homepage on the Internet]. DepoCyt ${ }^{\mathbb{B}}$ (cytarabine liposome injection) Prescribing Information. Available from: http://www.drugs.com/ pro/depocyt.html. Revised Sep 2011. Accessed November 11, 2011.

33. Drugs.com [homepage on the Internet]. DepoDur (morphine sulfate extended-release liposome injection) Prescribing Information. Available from: http://www.drugs.com/pro/depodur.html. Revised Jan 2008. Accessed November 11, 2011.

34. Patil SD, Burgess DJ. Liposomes, design and manufacturing. In: Burgess DJ, editor. Injectable Dispersed Systems: Formulation, Processing and Performance (Drugs and The Pharmaceutical Sciences Series). New York: Marcel Dekker; 2005:249-303.

35. Usonis V, Bakasénas V, Valentelis R, Katiliene G, Vidzeniene D, Herzog C. Antibody titres after primary and booster vaccination of infants and young children with a virosomal hepatitis A vaccine (Epaxal). Vaccine. 2003;21(31):4588-4592.

36. D'Acremont V, Herzog C, Genton B. Immunogenicity and safety of a virosomal hepatitis A vaccine (Epaxal) in the elderly. J Travel Med. 2006;13(2):78-83.

37. The electronic Medicines Compendium (eMC) [homepage on the Internet]. Epaxal Prescribing Information. Available from: http:// www.medicines.org.uk/EMC/medicine/12742/SPC/Epaxal/. Revised January 4, 2011. Accessed November 11, 2011

38. The electronic Medicines Compendium (eMC) [homepage on the Internet]. INFLEXAL V Prescribing Information. Available from: http://www.medicines.org.uk/emc/medicine/24941/SPC/inflexalv/. Revised Oct 2010. Accessed November 11, 2011.

39. Herzog C, Hartmann K, Künzi V, et al. Eleven years of Inflexal $\mathrm{V}$-a virosomal adjuvanted influenza vaccine. Vaccine. 2009;27(33): 4381-4387.

40. Zhang JA, Anyarambhatla G, Ma L, et al. Development and characterization of a novel Cremophor EL free liposome-based paclitaxel (LEP-ETU) formulation. Eur J Pharm Biopharm. 2005;59(1): 177-187.

41. Cattaneo AG, Gornati R, Sabbioni E, et al. Nanotechnology and human health: risks and benefits. J Appl Toxicol. 2010;30(8): 730-744

42. Michaelis U, Haas H. Targeting of cationic liposomes to endothelial tissue. In: Gregoriadis G, editor. Liposome Technology, Volume III: Interactions of Liposomes with the Biological Milieu. London, UK: Informa Healthcare; 2007:151-170.

43. Eichhorn ME, Becker S, Strieth S, et al. Paclitaxel encapsulated in cationic lipid complexes (MBT-0206) impairs functional tumor vascular properties as detected by dynamic contrast enhanced magnetic resonance imaging. Cancer Biol Ther. 2006;5(1):89-96.

44. Robert B, Campbell RB, Ying B, Kuesters GM, Hemphill R. Fighting cancer: from the bench to bedside using second generation cationic liposomal therapeutics. J Pharm Sci. 2009;98(2):411-429.

45. Li Z, Zhang Y, Wurtz W, et al. Characterization of nebulized liposomal amikacin (Arikace) as a function of droplet size. J Aerosol Med Pulm Drug Deliv. 2008;21(3):245-254.

46. Mossalam M, Dixon AS, Lim CS. Controlling subcellular delivery to optimize therapeutic effect. Ther Deliv. 2010;1(1):169-193.

47. Rodriguez MA, Pytlik R, Kozak T, et al. Vincristine sulfate liposomes injection (Marqibo) in heavily pretreated patients with refractory aggressive non-Hodgkin lymphoma: report of the pivotal phase 2 study. Cancer. 2009;115(15):3475-3482.

48. Krishna R, Webb MS, St Onge G, Mayer LD. Liposomal and nonliposomal drug pharmacokinetics after administration of liposomeencapsulated vincristine and their contribution to drug tissue distribution properties. J Pharmacol Exp Ther. 2001;298(3):1206-1212. 
49. Yarmolenko PS, Zhao Y, Landon C, et al. Comparative effects of thermosensitive doxorubicin-containing liposomes and hyperthermia in human and murine tumours. Int J Hyperthermia. 2010;26(5): 485-498.

50. Dromi S, Frenkel V, Luk A, et al. Pulsed-high intensity focused ultrasound and low temperature-sensitive liposomes for enhanced targeted drug delivery and antitumor effect. Clin Cancer Res. 2007;13(9): 2722-2727.

51. Zahid S, Brownell I. Repairing DNA damage in xeroderma pigmentosum: T4N5 lotion and gene therapy. J Drugs Dermatol. 2008;7(4):405-408.

52. Tari AM, Gutiérrez-Puente Y, Monaco G, et al. Liposome-incorporated Grb2 antisense oligodeoxynucleotide increases the survival of mice bearing bcr-abl-positive leukemia xenografts. Int $J$ Oncol 2007;31(5):1243-1250.

53. Pal A, Khan S, Wang YF, et al. Preclinical safety, pharmacokinetics and antitumor efficacy profile of liposome-entrapped SN-38 formulation. Anticancer Res. 2005;25(1A):331-341.

54. Dragovich T, Mendelson D, Kurtin S, Richardson K, Von Hoff D, Hoos A. A Phase 2 trial of the liposomal DACH platinum L-NDDP in patients with therapy-refractory advanced colorectal cancer. Cancer Chemother Pharmacol. 2006;58(6):759-764.

55. ClinicalTrials.gov [homepage on the Internet]. Prostaglandin E1 (Liprostin) treatment with lower limb angioplasty for peripheral arterial occlusive disease. Available from: http:/clinicaltrials.gov/ct2/show/ NCT00053716. Accessed November 11, 2011.

56. Powell E, Chow LQ. BLP-25 liposomal vaccine: a promising potential therapy in non-small-cell lung cancer. Expert Rev Respir Med. 2008;2(1):37-45.

57. Ohyanagi F, Horai T, Sekine I, et al. Safety of BLP25 liposome vaccine (L-BLP25) in Japanese patients with unresectable stage III NSCLC after primary chemoradiotherapy: preliminary results from a Phase I/II study. Jpn J Clin Oncol. 2011;41(5):718-722.

58. Stathopoulos GP, Boulikas T. Lipoplatin formulation review article J Drug Deliv. 2012;2012:581363.

59. Yu NY, Conway C, Pena RL, Chen JY. STEALTH liposomal CKD-602, a topoisomerase I iInhibitor, improves the therapeutic index in human tumor xenograft models. Anticancer Res. 2007;27(4B):2541-2545.

60. Hwang JH, Lim MC, Seo SS, Park SY, Kang S. Phase II study of belotecan (CKD 602) as a single agent in patients with recurrent or progressive carcinoma of uterine cervix. Jpn J Clin Oncol. 2011;41(5): 624-629.

61. Duffaud F, Borner M, Chollet P, et al. Phase II study of OSI-211 (liposomal lurtotecan) in patients with metastatic or loco-regional recurrent squamous cell carcinoma of the head and neck. An EORTC New Drug Development Group study. Eur J Cancer. 2004;40(18): 2748-2752.

62. Semple SC, Leone R, Wang J, et al. Optimization and characterization of a sphingomyelin/cholesterol liposome formulation of vinorelbine with promising antitumor activity. J Pharm Sci. 2005;94(5):1024-1038.

63. Mross K, Niemann B, Massing U, et al. Pharmacokinetics of liposomal doxorubicin (TLC-D99; Myocet) in patients with solid tumors: an open-label, single-dose study. Cancer Chemother Pharmacol. 2004;54(6):514-524.

64. Shaji J, Patole V. Protein and Peptide drug delivery: oral approaches. Indian J Pharm Sci. 2008;70(3):269-277.

65. Chen C, Han D, Cai C, Tang X. An overview of liposome lyophilization and its future potential. J Control Release. 2010;142(3):299-311.

66. EL-Neser OH, Yahiya SA, EL-Gazayerly ON. Effect of formulation design and freeze-drying on properties of fluconazole multilamellar liposomes. Saudi Pharm J. 2010;18:217-224.

67. Clemons KV, Stevens DA. Comparison of fungizone, Amphotec, AmBisome, and Abelcet for treatment of systemic murine cryptococcosis. Antimicrob Agents Chemother. 1998;42(4):899-902.

68. Wu SY, Putral LN, Liang M, et al. Development of a novel method for formulating stable siRNA-loaded lipid particles for in vivo use. Pharm Res. 2009;26(3):512-522.
69. Rahman AM, Yusuf SW, Ewer MS. Anthracycline-induced cardiotoxicity and the cardiac-sparing effect of liposomal formulation. Int $J$ Nanomedicine. 2007;2(4):567-583.

70. Lammers T, Hennink WE, Storm G. Tumour-targeted nanomedicines: principles and practice. Br J Cancer. 2008;99(3):392-397.

71. Harris L, Batist G, Belt R, et al. TLC D-99 Study Group. Liposomeencapsulated doxorubicin compared with conventional doxorubicin in a randomized multicenter trial as first-line therapy of metastatic breast carcinoma. Cancer. 2002;94(1):25-36.

72. O’Brien ME, Wigler N, Inbar M, et al. CAELYX Breast Cancer Study Group. Reduced cardiotoxicity and comparable efficacy in a phase III trial of pegylated liposomal doxorubicin $\mathrm{HCl}$ (CAELYX/Doxil) versus conventional doxorubicin for first-line treatment of metastatic breast cancer. Ann Oncol. 2004;15(3):440-449.

73. Hong RL, Tseng YL. Phase I and pharmacokinetic study of a stable, polyethylene-glycolated liposomal doxorubicin in patients with solid tumor. Cancer. 2001;91:1826-1833.

74. Tseng YL, Hong RL, Tao MH, Chang FH. Sterically stabilized anti-idiotype immunoliposomes improve the therapeutic efficacy of doxorubicin in a murine B-cell lymphoma model. Int J Cancer. 1999;80(5):723-730.

75. Chao TC, Wang WS, Yen CC, Chiou TJ, Liu JH, Chen PM. A doseescalating pilot study of sterically stabilized, pegylated liposomal doxorubicin (Lipo-Dox) in patients with metastatic breast cancer. Cancer Invest. 2003;21(6):837-847.

76. Hossann M, Wang T, Wiggenhorn M, et al. Size of thermosensitive liposomes influences content release. J Control Release. 2010;147(3): 436-443.

77. ClinicalTrials.gov [homepage on the Internet]. Phase 3 study of ThermoDox with Radiofrequency Ablation (RFA) in Treatment of Hepatocellular Carcinoma (HCC). Available from: http://clinicaltrials. gov/ct2/show/NCT00617981. Accessed November 11, 2011.

78. Mills JK, Needham D. Lysolipid incorporation in dipalmitoylphosphatidylcholine bilayer membranes enhances the ion permeability and drug release rates at the membrane phase transition. Biochim Biophys Acta. 2005;1716(2):77-96.

79. Needham D, Anyarambhatla G, Kong G, Dewhirst MW. A new temperature-sensitive liposome for use with mild hyperthermia: characterization and testing in a human tumor xenograft model. Cancer Res. 2000;60:1197-1201.

80. Banno B, Ickenstein LM, Chiu GN, et al. The functional roles of poly(ethylene glycol)-lipid and lysolipid in the drug retention and release from lysolipid-containing thermosensitive liposomes in vitro and in vivo. J Pharm Sci. 2010;99(5):2295-2308.

81. O'Byrne KJ, Thomas AL, Sharma RA, et al. A phase I dose-escalating study of DaunoXome, liposomal daunorubicin, in metastatic breast cancer. Br J Cancer. 2002;87(1):15-20.

82. Forssen EA, Coulter DM, Proffitt RT. Selective in vivo localisation of daunorubicin small unilamellar vesicles in solid tumors. Cancer Res. 1992;52(12):3255-3261.

83. Forssen EA, Ross ME. Daunoxome ${ }^{\sqrt{\mathbb{R}}}$ treatment of solid tumors: preclinical and linical investigations. J Liposome Res. 1994;4(1):481-512.

84. Gill PS, Wernz J, Scadden DT, et al. Randomized phase III trial of liposomal daunorubicin versus doxorubicin, bleomycin, and vincristine in AIDS-related Kaposi's sarcoma. J Clin Oncol. 1996;14(8): 2353-2364.

85. Szebeni J. Complement activation-related pseudoallergy: a new class of drug-induced acute immune toxicity. Toxicology. 2005;216:106-121.

86. Mehta RR, Burke TG. Membrane biophysical parameters influencing anthracycline action. In: Priebe W, editor. Anthracycline Antibiotics. New York: American Chemical Society Publication; 2004:222-240.

87. Fetterly GJ, Straubinger RM. Pharmacokinetics of paclitaxel-containing liposomes in rats. AAPS Pharm Sci. 2003;5(4):E32.

88. Fetterly GJ, Grasela TH, Sherman JW, et al. Pharmacokinetic/ pharmacodynamic modeling and simulation of neutropenia during phase I development of liposome-entrapped paclitaxel. Clin Cancer Res. 2008;14(18):5856-5863. 
89. Winer EP, Berry DA, Woolf S, et al. Failure of higher-dose paclitaxel to improve outcome in patients with metastatic breast cancer: cancer and leukemia group B Trial 9342. J Clin Oncol. 2004;22(11):2061-2068.

90. Bayraktar S, Bayraktar UD, Rocha-Lima CM. Recent developments in palliative chemotherapy for locally advanced and metastatic pancreas cancer. World J Gastroenterol. 2010;16(6):673-682.

91. Stegmann T, Morselt HW, Booy FP, et al. Functional reconstitution of influenza virus envelopes. EMBO J. 1987;6(9):2651-2659.

92. Glück R, Mischler R, Brantschen S, Just M, Althaus B, Cryz SJ Jr. Immunopotentiating reconstituted influenza virus virosome vaccine delivery system for immunization against hepatitis A. J Clin Invest. 1992;90(6):2491-2495.

93. Nicholson KG, Thompson CI, Klap JM, et al. Safety and immunogenicity of whole-virus, alum-adjuvanted whole-virus, virosomal, and whole-virus intradermal influenza A/H9N2 vaccine formulations. Vaccine. 2009;28(1):171-178.

94. Kanra G, Marchisio P, Feiterna-Sperling C, et al. Comparison of immunogenicity and tolerability of a virosome-adjuvanted and a split influenza vaccine in children. Pediatr Infect Dis J. 2004;23(4):300-306.
95. Bressler NM, Bressler SB. Photodynamic therapy with verteporfin (Visudyne): impact on ophthalmology and visual sciences. Invest Ophthalmol Vis Sci. 2000;41(3):624-628.

96. Photodynamic therapy of subfoveal choroidal neovascularization in age-related macular degeneration with verteporfin: one-year results of 2 randomized clinical trials - TAP report. Treatment of Age-Related Macular Degeneration With Photodynamic Therapy (TAP) Study Group. Arch Ophthalmol. 1999;117:1329-1345.

97. Drugs.com [homepage on the Internet]. MediGene reports additional phase II results of EndoTAG-1 for the treatment of triple receptornegative breast cancer Prescribing Information. Available from: http:// www.drugs.com/clinical_trials/medigene-reports-additional-phase-iiresults-endotag-1-triple-receptor-negative-breast-cancer-9689.html. Posted Jun 2010. Accessed November 15, 2011.

98. White SC, Lorigan P, Margison GP, et al. Phase II study of SPI-77 (sterically stabilised liposomal cisplatin) in advanced non-small-cell lung cancer. Br J Cancer. 2006;95(7):822-828.

99. Booser DJ, Esteva FJ, Rivera E, et al. Phase II study of liposomal annamycin in the treatment of doxorubicin-resistant breast cancer. Cancer Chemother Pharmacol. 2002;50(1):6-8.
International Journal of Nanomedicine

\section{Publish your work in this journal}

The International Journal of Nanomedicine is an international, peerreviewed journal focusing on the application of nanotechnology in diagnostics, therapeutics, and drug delivery systems throughout the biomedical field. This journal is indexed on PubMed Central, MedLine, CAS, SciSearch ${ }^{\circledR}$, Current Contents ${ }^{\circledR} /$ Clinical Medicine,

\section{Dovepress}

Journal Citation Reports/Science Edition, EMBase, Scopus and the Elsevier Bibliographic databases. The manuscript management system is completely online and includes a very quick and fair peer-review system, which is all easy to use. Visit http://www.dovepress.com/ testimonials.php to read real quotes from published authors. 